\title{
Sequence analysis of the drug-resistant rpoB gene in the Mycobacterium tuberculosis L-form among patients with pneumoconiosis complicated by tuberculosis
}

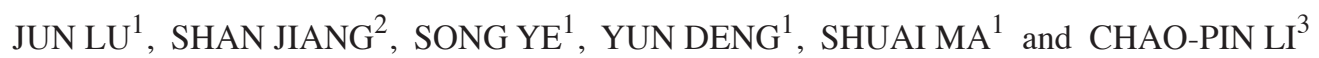 \\ ${ }^{1}$ Department of Pathogen Biology and Immunology, Anhui University of Science and Technology, Huainan, Anhui 232001; \\ ${ }^{2}$ Department of Mining Engineering, Huainan Vocational Technical College, Huainan, Anhui 232001; \\ ${ }^{3}$ Department of Medical Parasitology, Wannan Medical College, Wuhu, Anhui 241002, P.R. China
}

Received June 12, 2013; Accepted February 4, 2014

DOI: $10.3892 / \mathrm{mmr} .2014 .1948$

\begin{abstract}
The aim of the present study was to investigate the mutational characteristics of the drug-resistant Mycobacterium tuberculosis L-form of the rpoB gene isolated from patients with pneumoconiosis complicated by tuberculosis, in order to reduce the occurrence of the drug resistance of patients and gain a more complete information on the resistance of the Mycobacterium tuberculosis L-form. A total of 42 clinically isolated strains of Mycobacterium tuberculosis L-form were collected, including 31 drug-resistant strains. The genomic DNA was extracted, then the target genes were amplified by polymerase chain reaction and the hot mutational regions of the rpoB gene were analyzed by direct sequencing. The results revealed that no rpoB gene mutation was present in 11 rifampicin (RFP)-sensitive strains, while conformational changes were identified in 31 RFP-resistant strains. The mutation rate was $93.55 \%(29 / 31)$ in the resistant strains, and was frequently concentrated in codons $531(51.61 \% ; 16 / 31)$ and 526 (32.26\%; $10 / 31$ ), mainly occurring by case substitutions, including 27 unit point mutations and two two-point mutations. The novel mutation identified in codon 516 had not been previously reported. The substitution of highly-conserved amino acids encoded by the rpoB gene resulted in the molecular mechanism responsible for RFP resistance in the Mycobacterium tuberculosis L-form. This also demonstrated that the rpoB gene is diversiform.
\end{abstract}

Correspondence to: Dr Jun Lu, Department of Pathogen Biology and Immunology, School of Medicine, Anhui University of Science and Technology, No. 25 Dongshanzhong Road, Huainan, Anhui 232001, P.R. China

E.mail: cfdxlujun@126.com

Professor Chao-Pin Li, Department of Medical Parasitology, Wannan Medical College, No. 22 West of Wenchang Road, University Park, Wuhu, Anhui 241002, P.R. China

E.mail: cpli001@126.com

Key words: Mycobacterium tuberculosis L-form, drug-resistance, rpoB, sequence analysis

\section{Introduction}

Tuberculosis is a chronic infectious disease caused by the bacterium Mycobacterium tuberculosis, and it remains a significant public health risk worldwide. Cosmopolitan tuberculosis pestilence has quickly returned due to the misuse of antituberculosis drugs and infection with HIV that has been apparent since the 1980's $(1,2)$. Since becoming the first elected antituberculosis drug, the clinical therapeutic efficacy of RFP has severely degraded due to the appearance of drug-resistant strains and the L-form mutations of Mycobacterium tuberculosis. At present, drug resistance is an issue preventing the elimination of tuberculosis (3). According to the statistics, mutations in the rpoB gene in Mycobacterium tuberculosis account for $90 \%$ of the RFP-resistant strains, but there are no studies regarding the resistance of the L-form $(4,5)$. In the present study, a DNA sequence analysis technique was applied for investigating the mutational characteristics of rpoB in the Mycobacterium tuberculosis L-form, in order to provide a more complete understanding of its resistance.

\section{Materials and methods}

Experimental subjects. Subjects included male patients with pneumoconiosis complicated by tuberculosis $(n=114)$ who were aged between 41 and 70 years old, with a mean age of 53.35 \pm 9.28 years, and who were treated in the Affiliated Hospital of Anhui University of Science and Technology (Hefei, China) between July 2010 and July 2012. All the subjects were instructed to expectorate phlegm originating from the bottom of the trachea into sterile wide-mouthed bottles subsequent to gargling several times. The H37Rv quality control strain was provided by the Center of Biological Products of the Department of Health (Beijing, China). Patient consent was obtained from all the subjects. Approval was obtained from the Ethics Committee of the School of Medicine, Anhui University of Science and Technology (Huainan, China).

\section{Experimental methods}

DNA extraction. The sputum specimens of the patients were inactivated by autoclave. Genomic DNA was extracted using a 
Table I. Mutation characteristics of the rpoB gene in 31 clinical drug-resistant strains of Mycobacterium tuberculosis L-forms.

\begin{tabular}{|c|c|c|c|c|}
\hline Strain & Location of amino acids, codon & Change of codon & Change of amino acids & Percentage, $\%$ \\
\hline 10 & 531 & $\mathrm{TCG} \rightarrow \mathrm{TTG}$ & Ser $\rightarrow$ Leu & 32.26 \\
\hline 6 & 531 & $\mathrm{TCG} \rightarrow \mathrm{TGG}$ & Ser $\rightarrow$ Trp & 19.35 \\
\hline 5 & 526 & $\mathrm{CAC} \rightarrow \mathrm{GAC}$ & Gln $\rightarrow$ Asp & 16.13 \\
\hline 2 & 526 & $\mathrm{CAC} \rightarrow \mathrm{TAC}$ & $\mathrm{Gln} \rightarrow \mathrm{Tyr}$ & 6.45 \\
\hline 1 & 526 & $\mathrm{CAC} \rightarrow \mathrm{CTC}$ & $\mathrm{Gln} \rightarrow \mathrm{Leu}$ & 3.23 \\
\hline 1 & 526 & $\mathrm{CAC} \rightarrow \mathrm{CGC}$ & $\mathrm{Gln} \rightarrow \mathrm{Arg}$ & 3.23 \\
\hline 1 & 526 & $\mathrm{CAC} \rightarrow \mathrm{GTC}$ & $\mathrm{Gln} \rightarrow$ Val & 3.23 \\
\hline 1 & 516 & $\mathrm{GAC} \rightarrow \mathrm{GGC}$ & Asp $\rightarrow$ Gly & 3.23 \\
\hline 1 & 511,526 & $\mathrm{CTG} \rightarrow \mathrm{CCG}, \mathrm{CAC} \rightarrow \mathrm{CTC}$ & Leu $\rightarrow$ Pro, Gln $\rightarrow$ Leu & 3.23 \\
\hline 1 & 526,531 & $\mathrm{CAC} \rightarrow \mathrm{CTC}, \mathrm{TCG} \rightarrow \mathrm{TGG}$ & Gln $\rightarrow$ Leu, Ser $\rightarrow$ Trp & 3.23 \\
\hline 2 & - & - & - & 6.45 \\
\hline
\end{tabular}

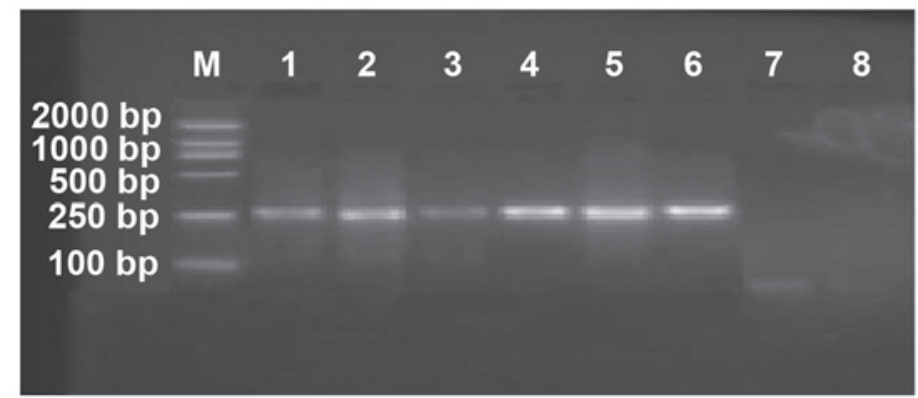

Figure 1. Detection of the amplification products of rpoB by polymerase chain readtion in clinical sputum specimens. Lane M, DL2000 marker (2000, 1000, 500, 250 and $100 \mathrm{bp}$ ); lane 1, the quality control strain (H37Rv); lane 2-6, clinical rifampicin-resistant strains with rpoB mutation; lane 7, clinical rifampicin-sensitive strain to rpoB; and lane 8, negative control.

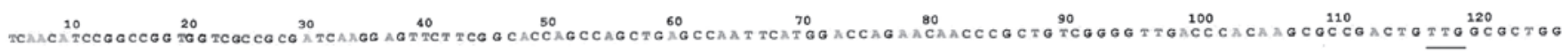
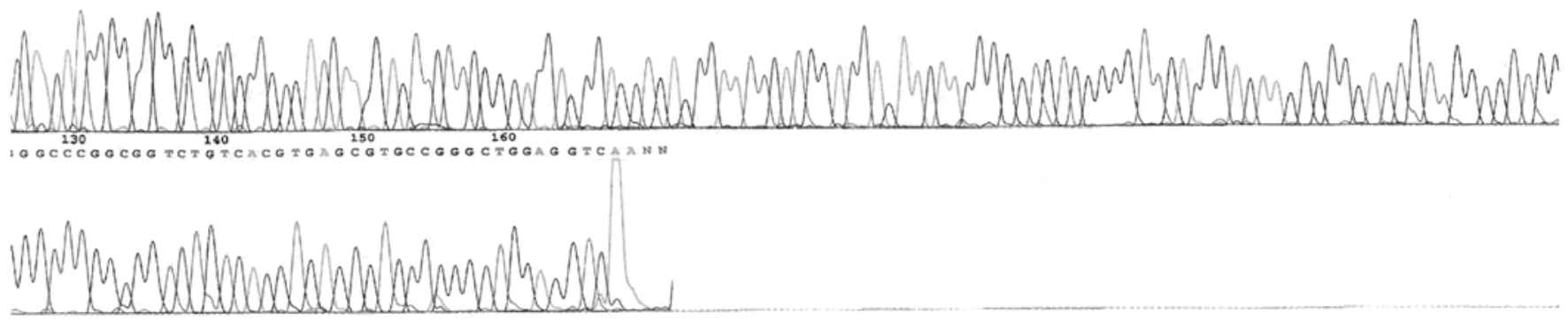

Figure 2. Sequence analysis of rpoB DNA in the clinically isolated Mycobacterium tuberculosis L-form; codon 531, TCG $\rightarrow$ TTG.

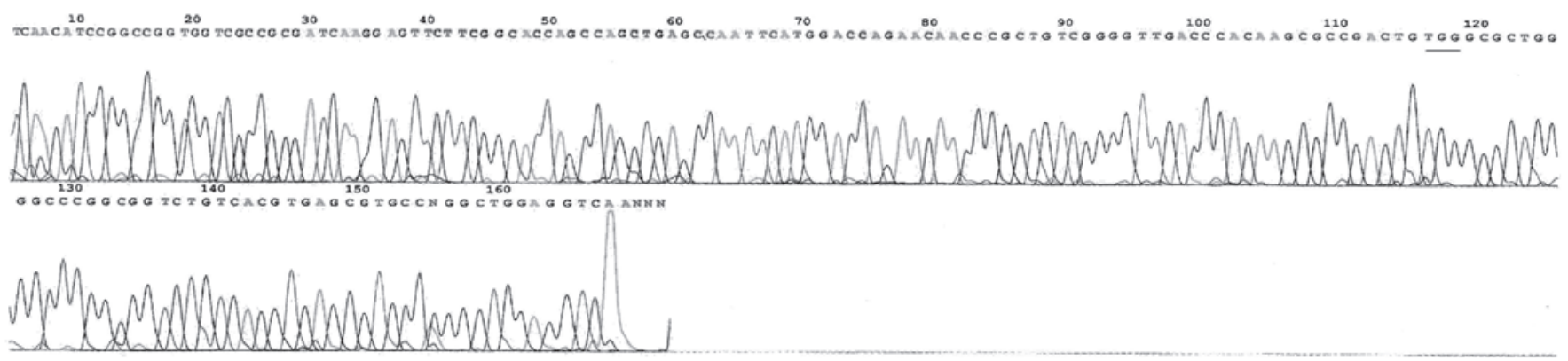

Figure 3. Sequence analysis of rpoB DNA in the clinically isolated Mycobacterium tuberculosis L-form; codon 531, TCG $\rightarrow$ TGG. 


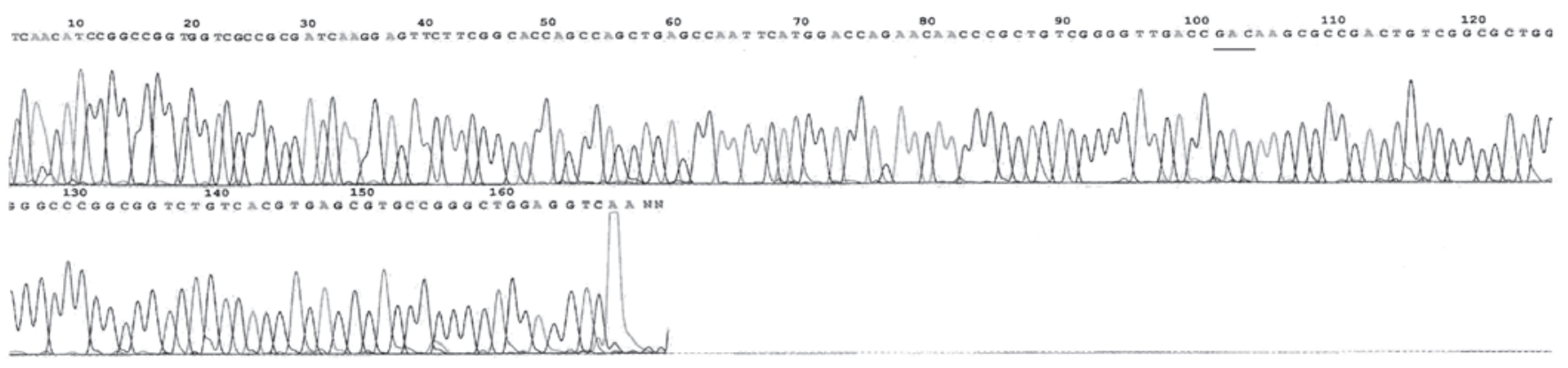

Figure 4. Sequence analysis of rpoB DNA in the clinically isolated Mycobacterium tuberculosis $\mathrm{L}$-form; codon, $526 \mathrm{CAC} \rightarrow \mathrm{GAC}$.

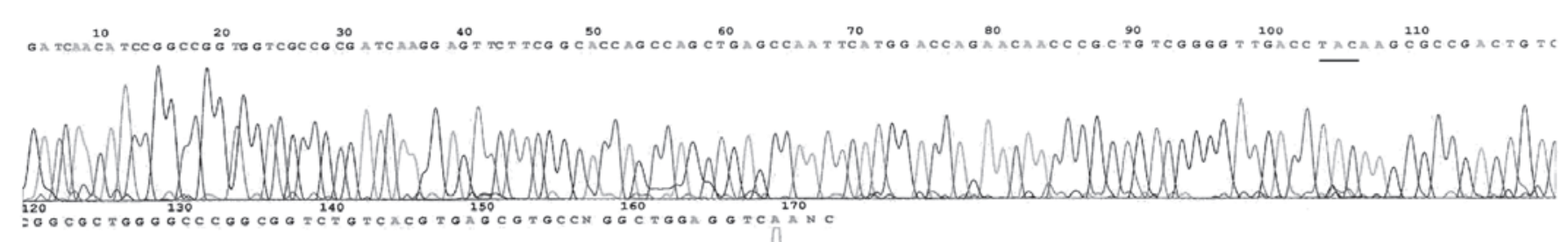

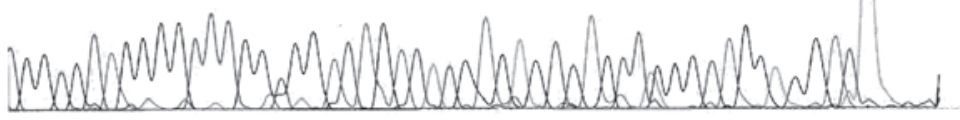

Figure 5. Sequence analysis of rpoB DNA in the clinically isolated Mycobacterium tuberculosis L-form; codon, 526 CAC $\rightarrow$ TAC.

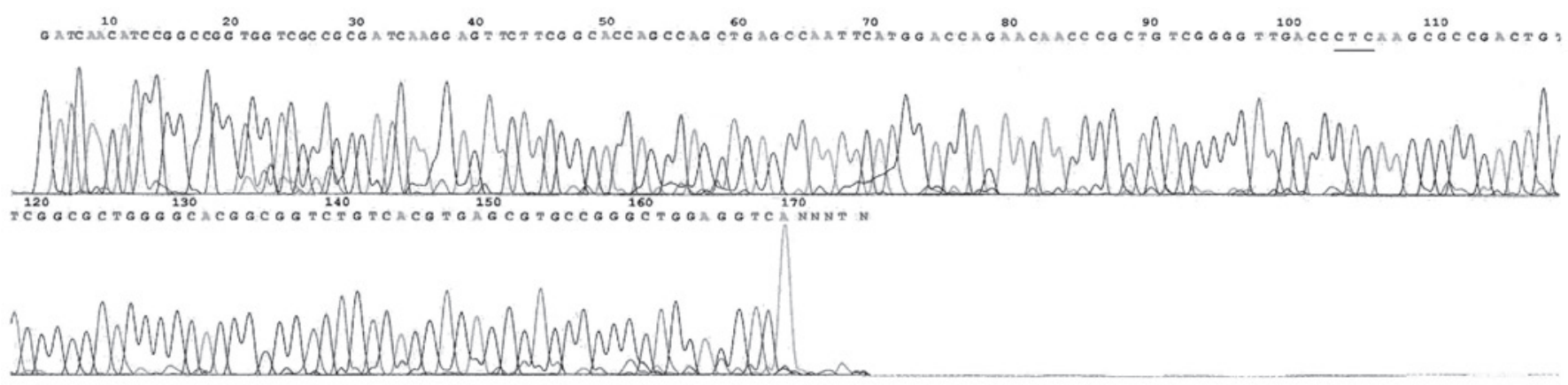

Figure 6. Sequence analysis of rpoB DNA in the clinically isolated Mycobacterium tuberculosis $\mathrm{L}$-form; codon, $526 \mathrm{CAC} \rightarrow \mathrm{CTC}$.

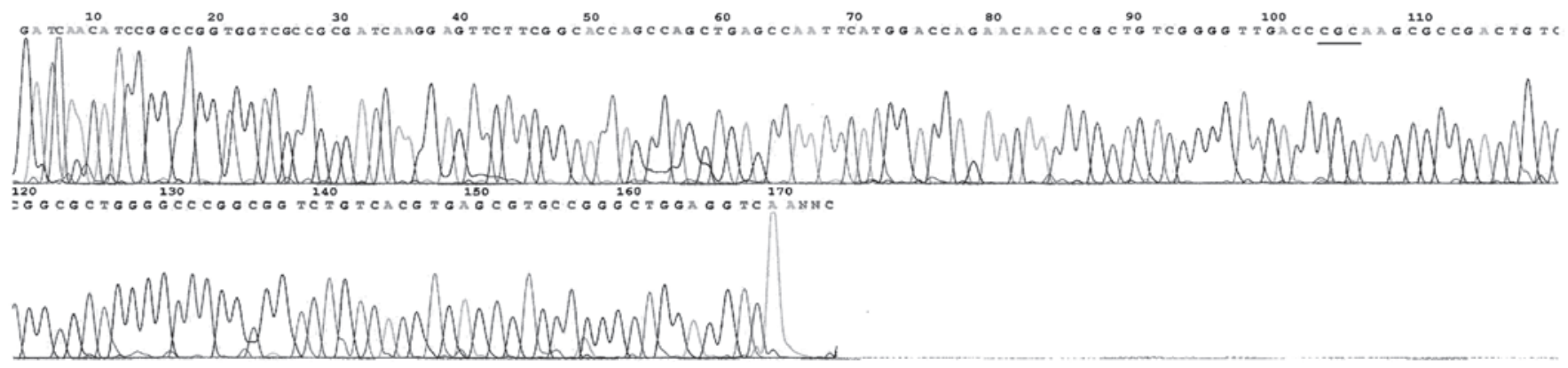

Figure 7. Sequence analysis of rpoB DNA in the clinically isolated Mycobacterium tuberculosis L-form; codon, 526 CAC $\rightarrow$ CGC.

DNA extraction kit (Takara Biotech Co., Ltd., Dalian, China). The inactivated specimens were lysed with $200 \mu 1$ DNA lysate (10 mmol/1 Tris-HCl, $100 \mathrm{mmol} / \mathrm{l} \mathrm{NaCl}, 25 \mathrm{mmol} / \mathrm{l}$ EDTA, $1 \% \mathrm{SDS}, 0.2 \mathrm{mg} / \mathrm{ml}$ proteinase $\mathrm{K}$ ) and incubated at $55^{\circ} \mathrm{C}$ for
1-3 h, then at $95^{\circ} \mathrm{C}$ for $5 \mathrm{~min}$. The lysate was extracted twice with phenol:chloroform:isoamyl alcohol (volume ratio 25:24:1). DNA was precipitated by adding ammonium acetate. 2.5 volumes of pure ethanol were added, followed by incubation 


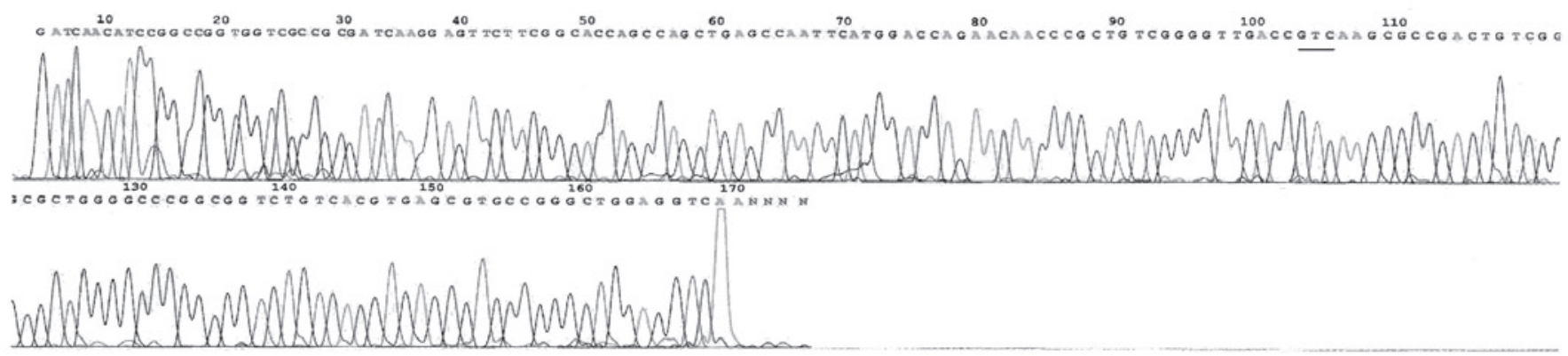

Figure 8. Sequence analysis of rpoB DNA in the clinically isolated Mycobacterium tuberculosis L-form; codon, 526 CAC $\rightarrow$ GTC.

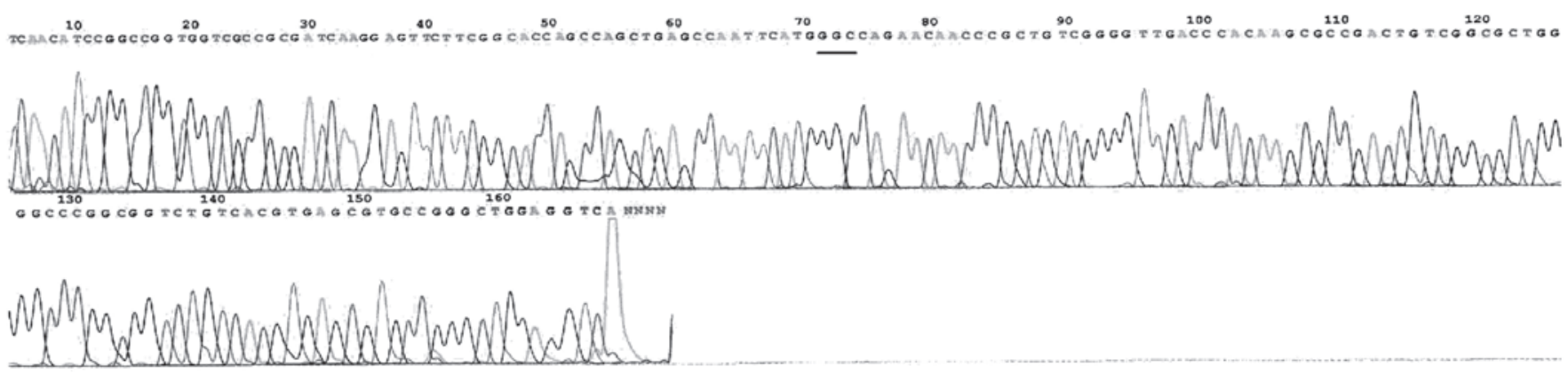

Figure 9. Sequence analysis of rpoB DNA in the clinically isolated Mycobacterium tuberculosis L-form; codon, 516 GAC $\rightarrow \mathrm{GGC}$.

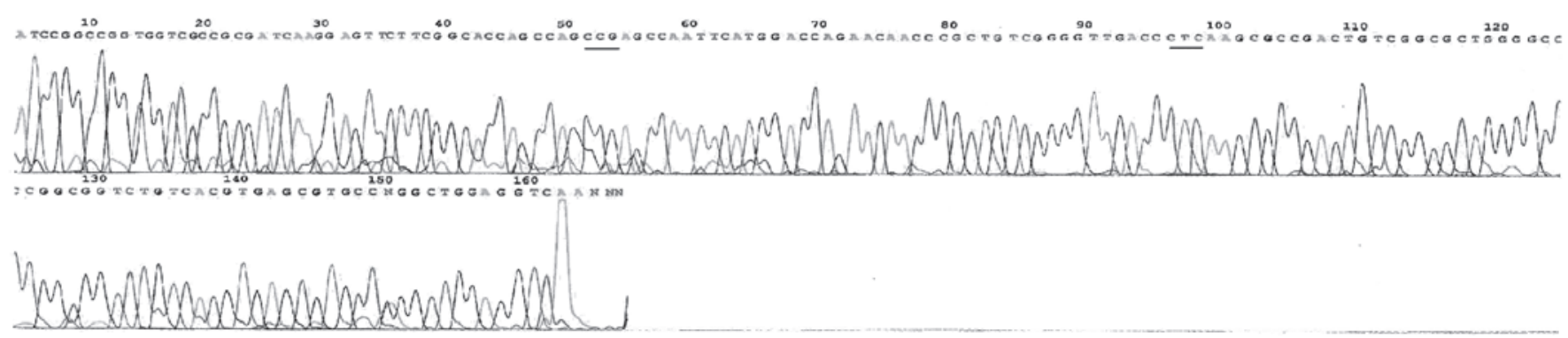

Figure 10. Sequence analysis of rpoB DNA in the clinically isolated Mycobacterium tuberculosis $\mathrm{L}$-form; codon, $511 \mathrm{CTG} \rightarrow \mathrm{CCG}$ and codon, $526 \mathrm{CAC} \rightarrow \mathrm{CTC}$.

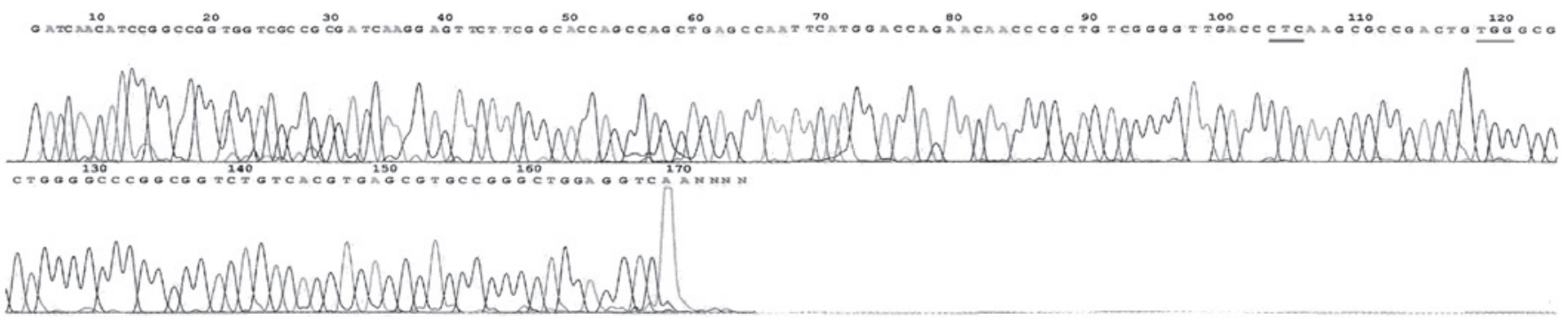

Figure 11. Sequence analysis of rpoB DNA in the clinically isolated Mycobacterium tuberculosis $\mathrm{L}$-form; codon, $526 \mathrm{CAC} \rightarrow \mathrm{CTC}$ and codon, $531 \mathrm{TCG} \rightarrow \mathrm{TGG}$.

at $-20^{\circ} \mathrm{C}$ overnight. DNA was pelleted by centrifugation at $12,000 \mathrm{x}$ g for $15 \mathrm{~min}$, washed with $70 \%$ ethanol, air-dried and dissolved in the TE buffer $[10 \mathrm{mmol} / \mathrm{l}$ Tris- $\mathrm{HCl}(\mathrm{pH} 7.4)$, $1 \mathrm{mmol} / \mathrm{l}$ EDTA] (6).

Primer contrivance. The primer was synthesized by Sangon Biotect Co., Ltd., (Shanghai, China) based on the conserved Mycobacterium tuberculosis genomic DNA sequence (a 69-bp mutational duplication conserved sequence). The primer sequences of rpoB used in this experiment were as follows: Forward: 5'-CGG ATG ACC ACC CAGG AC-3' and reverse: 5'-GGT TTA GAT CGG CAC AT-3'; product size, 258 bp.

PCR analysis and sequence analysis. The total PCR reaction volume was $50 \mu \mathrm{l}$ and included $5.0 \mu \mathrm{l} 10 \mathrm{X}$ buffer $(15 \mathrm{mmol} / \mathrm{l}$ 
$\left.\mathrm{MgCl}_{2}\right), 4.0 \mu \mathrm{l}$ dNTPs $(200 \mu \mathrm{mol} / \mathrm{l}), 1.0 \mu \mathrm{l}$ of each primer $(25 \mathrm{pmol} / \mu \mathrm{l}), 0.5 \mu \mathrm{l}$ Taq DNA polymerase $(5 \mathrm{U} / \mu \mathrm{l})$ and $4 \mu \mathrm{l}$ DNA template. Deionized water was added for a total volume of $50 \mu \mathrm{l}$. The reaction conditions were: $95^{\circ} \mathrm{C}$ for $5 \mathrm{~min}$ of denaturation, then $94^{\circ} \mathrm{C}$ for $30 \mathrm{sec}, 55^{\circ} \mathrm{C}$ for $90 \mathrm{sec}$ and $72^{\circ} \mathrm{C}$ for $30 \mathrm{sec}$, for 33 cycles in total, followed by maintenance at $72^{\circ} \mathrm{C}$ for $10 \mathrm{~min}$. The amplified product $(5 \mu \mathrm{l})$ was determined by electrophoresis with a $2 \%$ agarose gel (containing $0.5 \mathrm{mg} / \mathrm{ml}$ ethidium bromide). Images were captured and analyzed with Image Master TotalLab software (TotalLab, Ltd., Newcastle, UK). This revealed whether the rpoB mutation was present, indicated by the specific bands at $258 \mathrm{bp}$. The sequence determination of the DNA sequences of the PCR product was detected by an ABI PRISM 7700 sequencer (Takara Biotech Co., Ltd.).

Statistical analysis. Statistical analyses were performed using SPSS 12.0 software (SPSS, Inc., Chicago, IL, USA).

\section{Results}

PCR analysis. In the total 42 cases of Mycobacterium tuberculosis $\mathrm{L}$-form isolated from the sputum samples, $31 \mathrm{RFP}$-resistant strains and 11 RFP-sensitive strains were identified (Fig. 1).

Sequence analysis of DNA of Mycobacterium tuberculosis $L$-form. In total, there were 29 mutational strains of the rpoB gene within the 31 RFP-resistant strains. The rate of mutation was observed to be $93.55 \%$ (29/31; Table I), mainly concentrated in codon $531(51.61 \%, 16 / 31)$ and $526(32.26 \%, 10 / 31)$ and occurring by base substitutions, including 27 unit point mutations and two two-site point mutations. The mutation of codon 516 was a novel observation (Fig. 2-11). No rpoB mutation was identified in the 11 RFP-sensitive strains.

\section{Discussion}

Pneumoconiosis is a significant occupational disease in employees of coal mines, and once pneumoconiosis associates with tuberculosis, it develops more rapidly and worsens the tuberculosis of the patient. The prognoses of patients with the disease appear to be poor, and the therapeutic effects on these cases are not good, as may be expected. At present, the therapeutic regimen includes treating the pneumoconiosis and the tuberculosis using antituberculosis drugs, since there is a lack of radically curative drugs for the treatment of pneumoconiosis.

The molecularanti-RFPmechanism of Mycobacterium tuberculosis was correlated with the mutation of the rpoB gene, which was coded by the $\beta$ subunit of RNA polymerase. RFP usually inhibits the transcription of RNA polymerase with the purpose of killing infected cells $(7,8)$. In total, $96 \%$ of drug-resistant strains are caused by mutations in the rpoB gene, by an insertion or deletion of basic groups, mainly concentrated around the determining $\sim 80$-bp region of RFP. In 35 types of mutations, $43 \%$ are missense mutations (9). Mutations in site 513 have been shown to result in greater drug resistance [minimal inhibition concentration $(\mathrm{MIC})>32 \mu \mathrm{g} / \mathrm{ml}$, while mutations at sites 514, 521 and 533 lead to lower drug resistance (MIC<12.5 $\mu \mathrm{g} / \mathrm{ml})(10-12)$. In theory, drug-resistant strains of Mycobacterium tuberculosis may occur due to two main reasons. Firstly, resistance may occur due to a mutation in the $\beta$ subunit of the RNA polymerase of the target molecule by drug action. Secondly, the ingesting capability of the infected cells may be decreased due to a change in the osmosis of the cell wall (13).

The Mycobacterium tuberculosis L-form is also known as the Mycobacterium cell wall-deficient form; in 1960, Mattmand (14) explained its biological characteristics in detail. It was demonstrated that the changes of the L-form were evident due to the absence of the cell wall either partly or completely, thus affecting the biological characteristics, drug sensitivity and DNA. The L-form is considered a type of mutation. This mutation may be induced by a number of factors, including chemotherapeutics, lysozymes and bacteriophages. Once Mycobacterium tuberculosis L form variation occurs, it continues to possess pathogenicity, causing chronic transformation of the disease process, which leads to a worse prognosis. This has resulted in problems in the diagnosis and treatment of tuberculosis (15).

In the present study, the results of the PCR analysis demonstrated that there were 29 mutational strains of the rpoB gene within the 31 RFP-resistant strains; the mutation rate was $93.55 \%(29 / 31)$. In the resistant strains, the mutations were mainly located in codons $531(51.61 \% ; 16 / 31)$ and $526(32.26 \% ; 10 / 31)$, occurring by base substitutions. The former site included 10 strains of $\mathrm{Ser} \rightarrow \mathrm{Leu}(\mathrm{TCG} \rightarrow \mathrm{TTG})$ and six strains of $\operatorname{Ser} \rightarrow \operatorname{Trp}(\mathrm{TCG} \rightarrow \mathrm{TGG})$, while the latter contained mainly Gln $\rightarrow$ Asp $(C A C \rightarrow$ GAC) substitutions. These results revealed that unit point mutations of the rpoB gene of Mycobacterium tuberculosis L-form are located in codons 531 and $526(83.87 \% ; 26 / 31)$, as mentioned in previous studies $(10,16)$. The point mutation of codon 516 , which has not been previously reported, was a same-sense mutation. A total of 11 RFP-sensitive strains were not mutations of the ropB gene.

Furthermore, two strains of two-site point mutations were identified, one at codons $526(\mathrm{Gln} \rightarrow$ Leu) and $531(\mathrm{Ser} \rightarrow \operatorname{Trp})$ and the other at codons 511 (Leu $\rightarrow$ Pro) and 526 (Gln $\rightarrow$ Leu). The mutation rate was $6.45 \%(2 / 31)$, appreciably lower than the rate of mutation reported inland and overseas $(10,16)$. This demonstrated that the type of conjoined mutation was a point mutation, and no same-sense mutation was detected. The possible cause may be related to the novel mutational characteristics of the Mycobacterium tuberculosis L-form and the effects of sampling errors, and thus further studies on a greater sample size are required in order to verify this conclusion.

\section{Acknowledgements}

This study was supported by grants from the National Natural Science Foundation of China (grant no. 81172778) and the Natural Science Foundation of Anhui Province (grant nos. KJ2010A087 and KJ2012A081).

\section{References}

1. Li YL: Microbiological examination method of common pathogenic bacteria infection. In: The Book of Chinese Medical Laboratory Science. First Edition. People's Medical Publishing House Co. Ltd, Beijing, pp1119-1120, 2000 (In Chinese). 
2. du Toit LC, Pillay V and Danckwerts MP. Tuberculosis chemotherapy: current drug delivery approaches. Respir Res 7: 118, 2006.

3. Telenti A and Iseman M: Drug-resistant tuberculosis: what do we do now? Drugs 59: 171-179, 2000.

4. Valim AR, Rossetti ML, Ribeiro MO and Zaha A: Mutations in the rpoB gene of multidrug-resistant Mycobacterium tuberculosis isolates from Brazil. J Clin Microbiol 38: 3119-3122, 2000.

5. Ahmad S, Mokaddas E and Fares E: Characterization of rpoB mutations in rifampin-resistant clinical Mycobacterium tuberculosis isolates from Kuwait and Dubai. Diagn Microbiol Infect Dis 44: 245-252, 2002.

6. Cheng XD, Yu WB, Su MQ, Bie LF, et al: Study on M. tuberculosis isoniazid-resistant isolates by multi-PCR. Journal of Fourth Military Medical University 24: 849-851, 2003 (In Chinese)

7. Pozzi G, Meloni M, Iona $\mathrm{E}$, et al: $\operatorname{ropB}$ mutations in multidrug-resistant strains of Mycobacterium tuberculosis isolated in Italy. J Clin Microbiol 37: 1197-1199, 1999.

8. Morris S, Bai GH and Suffys P: Molecular mechanisms of multiple drug resistance in clinical isolates of Mycobacterium tuberculosis. J Infect Dis 171: 954-960, 1995.

9. Wu X, Zhuang Y, Zhang J, et al: Study on the molecular mechanism of multi-drug resistance in clinical isolates of Mycobacterium tuberculosis. Zhonghua Jie He He Hu Xi Za Zhi 20: 332-335, 1997 (In Chinese).
10. Isakova ZhT, Pak OA, Iusupova Elu, et al: Use of biological microchips in the determination of drug-resistance of Mycobacterium tuberculosis to rifampicin. Probl Tuberk Bolezn Legk 8: 50-53, 2005 (In Russian).

11. Heep M, Rieger U, Beck D and Lehn N: Mutations in the beginning of the rpoB gene can induce resistance to rifamycins in both Helicobacter pylori and Mycobacterium tuberculosis. Antimicrob Agents Chemother 44: 1075-1077, 2000.

12. Kapur V, Li LL, Iordanescu S, et al: Characterization by automated DNA sequencing of mutations in the gene (rpoB) encoding the RNA beta subunit in rifampin-resistant Mycobacterium tuberculosis strains from New York City and Texas. J Clin Microbiol 32: 1095-1098, 1994.

13. Wang $\mathrm{H}$ and Chen $\mathrm{Z}$ : Observations of properties from the $\mathrm{L}$-form of M.tuberculosis induced by the antituberculosis drugs. Zhonghua Jie He He Hu Xi Za Zhi 24; 52-55, 2001 (In Chinese).

14. Mattmand LH: Lvariation in mycobacteria. Am Rev Respir Dis 202: $82-85,1960$.

15. Lu J, Ye S and Li CP: Application of PCR-SSCP technique on detecting Drug Resistant Genetic Mutation in M. tuberculosis L-forms among pneumoconiosis patients complicated with tuberculosis in Huainan mining district. Chin J Ind Hyg Occup Dis 25: 369-370, 2007 (In Chinese)

16. Cao LX, Wu XQ, Liang JQ, et al: Rapid detection of rpoB mutations in Mycobacterium tuberculosis by gene array. Chin Tuberc Respir Dis 27: 332-335, 2004 (In Chinese). 